2) The reactions of $\beta-G$ in the tongue are similar to those of sulfhydryl groups.

Dr. Mori :

1) We have nothing about the inhibitor.

2) The post azo-coupling method using 6-bromo-2-naphthyl complexs or 6-benzoyl-2-naphthyl complexs stains the epithelium of the tongue.

Its localization is quite similar to that of $-\mathrm{SH}$ groups, and of ten to the reaction of protein groups by diazonium salts.

\title{
Studies on Phosphodiesterase
}

\author{
Hiroshi Nishi*, Makoto Sekrmoto*, Takawo OHtsu** \\ and Hideo TAKamatsu*** \\ * The Midorigaoka Sanatorium in Kanagawa Prefecture. \\ ** Japan Gasoline Co., Ltd. \\ *** The Department of Pathology, Tuberculosis Research Institute \\ Kyoto University. (Director: Prof. H. Takamatsu)
}

\section{Introduction}

Many biochemical and histochemical studies have been reported on a group of enzymes which are classified as phosphatases, but there still remain many areas to be investigated, especially with regard to the specificities of these enzymes. The relationship between the enzymes and the chemical structures of their substrates, their optimal ranges, the effects of activators and inhibitors, and the effects of coexisting substance in crude enzyme materials, are among the important areas of study.

A phosphodiesterase splits one $\mathrm{P}-\mathrm{O}$ bond of dinaphthyl phosphate and produce one naphthol and one naphthyl phosphate. A phosphomonoesterase is able to split the $\mathrm{P}-\mathrm{O}$ bond of the resulting napthyl phosphate; thus the final products of the combined action of the two enzymes are two naphthols and one phosphoric acid.

Histochemical studies have shown that both the phosphomonoesterase and the phosphodiesterase activities are present in identical tissue sites; therefore it would appear that their functions in the tissue are closely connected.

The present report is concerned with studies on methods for the separation of phosphomonoesterase and phosphodiesterase by two procedures, paper chromatography and paper electrophoresis.

\section{Material and Method}

Enzyme activites were extracted with acetone from human intestinal mucous membrane and an aquous solution of this extract was applid as a streak on paper. Paper chromatography was performed in the usual way, except for 
methods for detection of the enzymes. Whatman No. 3MM paper and the two solvents, $0.33 \mathrm{~mol}$. aqueous sodium chloride and acetone water mixture (2:3), were employed. The paper was developed at $5^{\circ} \mathrm{C}$ in the refrigerator for about 4 hours and dried as soon as possible at a low temperature. The dried chromatogram was then drawn quickly through a $0.05 \%$ celloidin.

The conditions employed for paper electrophoresis were as follows: A current of $0.2 \mathrm{~mA} / \mathrm{cm}$., at $160 \mathrm{~V}$ was applied at $5^{\circ} \mathrm{c}$ for 5 hours with veronal buffer, $\mathrm{pH} 8.6$. The treatment of the finished paper was the same as in paper chromatography. The developed paper was laid on an agar plate containing the enzyme substrate for the detection of enzyme according to Giri's method but, a histochemical technique, the azo dye method, was applied on the celloidin coated paper. The substrates, $\boldsymbol{\beta}$-naphthyl phosphate and $\mathrm{di}-\boldsymbol{\beta}$-naphthyl phosphate were synthetized according to Freedman's method.

\section{Results and Discussion}

The results of paper chromatography and paper electrophoresis are shown in Fig. 3. The location of phosphatase is visible as a purplish blue area. (Fig. 2 and Fig. 3)

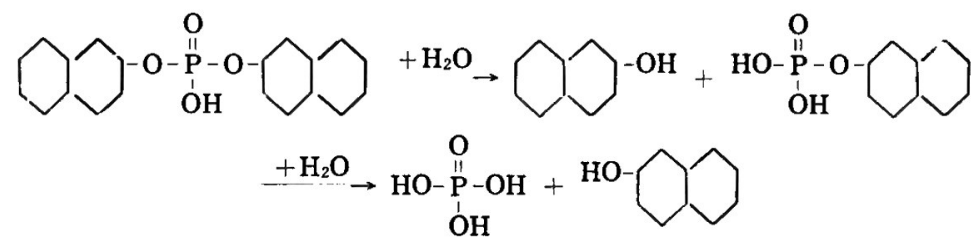

Fig. 1 .

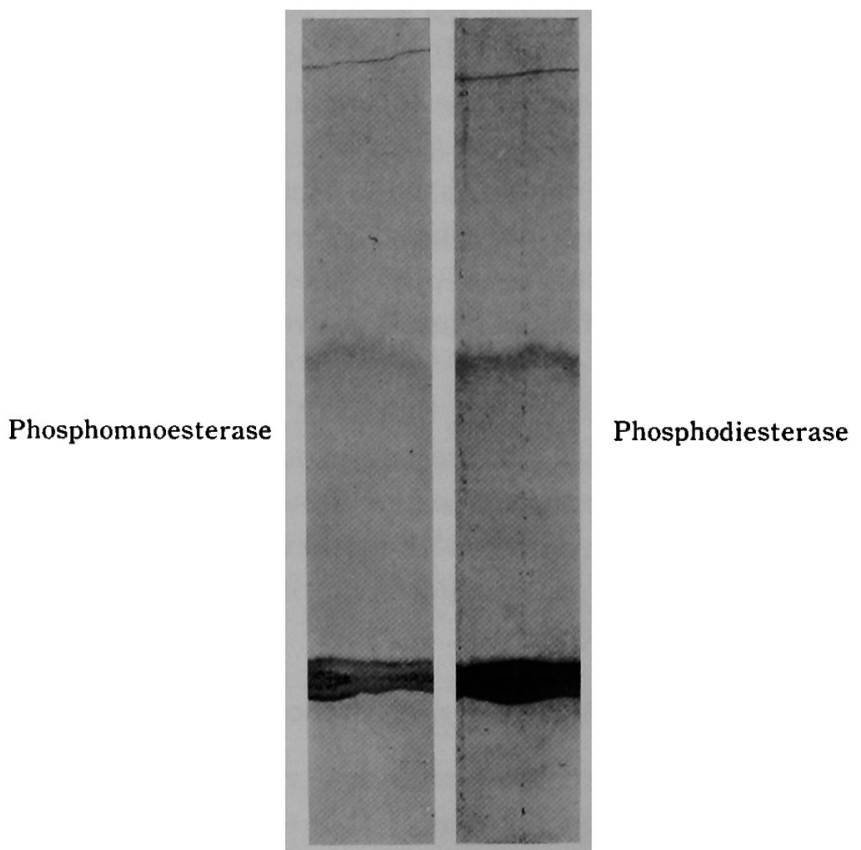

Fig. 2. Paper chromatogram of phosphomonoesterase and phosphodiesterase 
Phosphomonoesterase

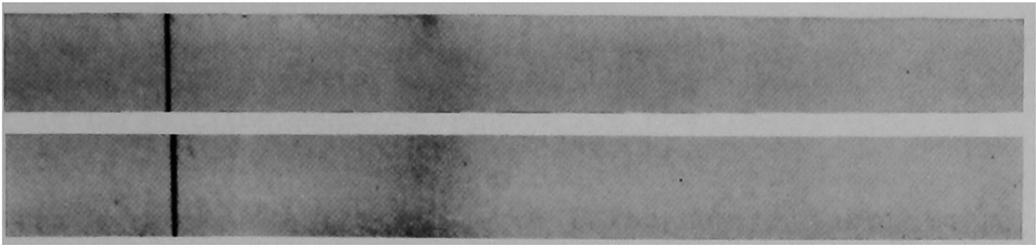

Phosphodiesterase

Fig. 3. Paper electrophoresis of phosphomonoestrase and phosphodiesterase

When $\beta$-napthyl phosphate and $\mathrm{di}-\boldsymbol{\beta}$-naphthyl phosphate were each tested as substrates, the activities of the mono- and diesterases were found not separated after paper chromatography and paper electrophoresis in two solvent systems. These results showed that the phosphodiesterase and phosphomonoesterase activities could not be separated under present conditions; therefore other techniques were tried. A modified histochemical technique is easily applicable to the chromatograms and the location of enzymes could be detected. When the substrate is di- $\beta$-naphthyl phosphate, $\beta$-napththol is liberated first by the diesterase activity, and then phosphoric acid is produced by the monoesterase action. Therefore, if o-dianisidine and calcium ion are adedd to the substrate mixture according to Takamatsu's method, the free $\beta$-naphthol reacts with the diazonium compound and becomes an azo dye, but calcium phosphate is produced as well in the monoesterase reaction. The color of the reaction in the presence of calcium phosphates is quite different from that in its absence; therefore the detection of the two enzymes is possible. (Fig. 4)

However, the existence of two different enzymes still could not be shown by this method. These results suggest that a single enzyme may be involved.

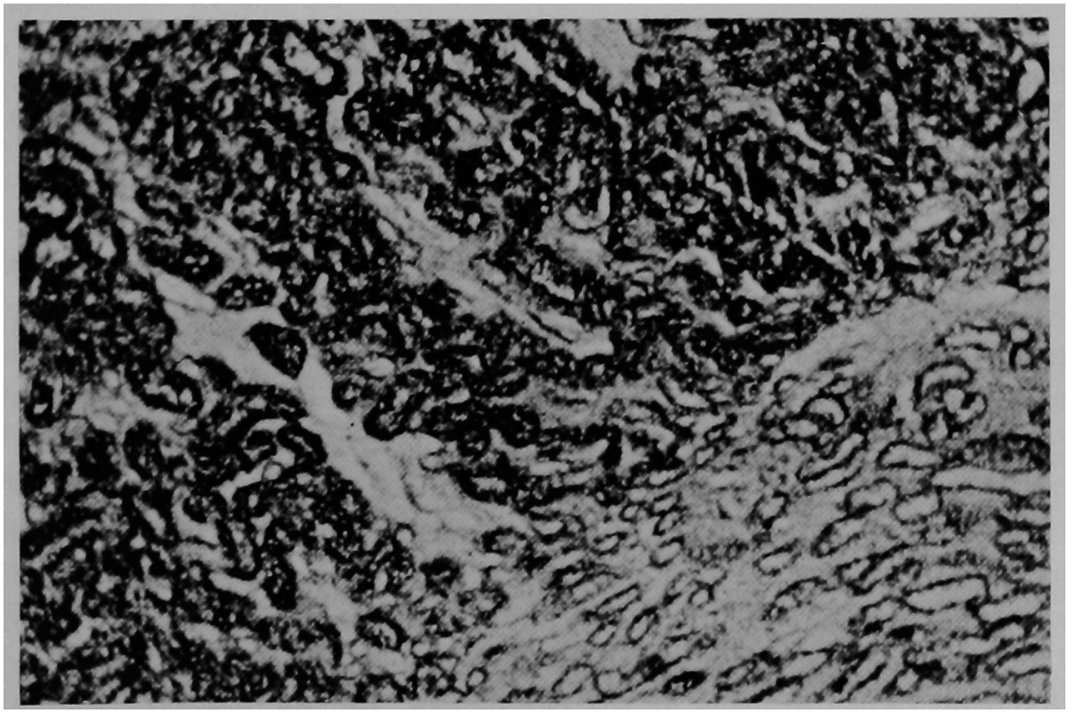

Fig. 4. The double reaction on rat kidney. Two colors of the both reaction are hardly discriminative with each other in the black and white photograph. 


\title{
Summary
}

Phosphatase activity which was extracted from human intestinal mucous membrane was subsected to paper chromatography and paper elecrophoresis, using as substrate naphthyl phosphate and di-naphthyl phosphate.

Phosphomonoesterase and phosphodiesterase activities were located in the same position on the chromatogram. A direct developing method was employed for detection of enzymatic activities.

The authors showed some important evidences on the subject, but the problem of the specificity of phosphodiesterase seems to be still unresolved.

1) Giri, K. V., et al Biochem. J. 51, 123. 128 (1952).

2) Friedman Orrie and Seligman A. M. 72, 624-625 (1950). 3) Takamatsu H., et al., Trans. Soc. Path. Jap. 39, Ed. Gen. (1950). 4) Roche, J., The Enzymes. (Ed. Summer J. B. and Myrback, K.) Vol. 1p. 473, Acad. Press. New York. (1950). 5) Gomori, G., J. Lab. \& Clin. Med. 37, 526 (1951). 6) Gomori, G., Microscopic Histochemistry, Univ. Chicago Press, Chicago, (1952).

\section{Histochemical Studies on Experimental Carcinogenesis in the Submaxillary Gland of the RAT With or Without Duct-ligation}

\author{
Akitoshi Sugimoto, Toshio Yagi, Haruo Hiraoka, \\ Kazuo Sakamoto, Fusazo Taguchi, and Kinji Окamoto \\ The Department of Oral Pathology, Osaka University Dental School, Osaka, Japan \\ (Director: Prof. Dr. T. Terasaki)
}

It has been reported by Sugimoto ${ }^{1,2}$ and by other investigators ${ }^{8-7}$ that the submaxillary salivary gland of the rat shows some remarkable regenerating changes following ligation of the excretory duct. As it is also well known that in the salivary gland, benign and malignant tumors can be induced experimentally by chemical carcinogens, ${ }^{8-14}$ a problem may be raised as to whether ductligation has any influence on carcinogenesis in the salivary gland. The present study is concerned with histological and histochemical observations on the rat submaxillary gland in the earlier stage of the experimental carcinogenic process with and without duct-ligation. Recently, Standish and Schafer ${ }^{15}$ published a similar investigation, employing only the histological method and using 7, 12dimethyl-benz $(\alpha)$-anthracene as the carcinogen. In the present study, histochemical observations are carried out employing 20-methylcholanthrene and 3,4benzpyrene as chemical carcinogens. 